\title{
Spray drying technology: an overview
}

\author{
R. P. Patel, M. P. Patel and A. M. Suthar \\ Department of Pharmaceutics, S. K. Patel College of Pharmaceutical Education and Research, Ganpat University, \\ Kherva, Mehsana, Gujarat-382 711, India. \\ Raka_77us@yahoo.com
}

Abstract: This systemic review covers the design and critical elements of spray drying, types of spray drier, critical parameters of spray drying, innovations in spray drying, and its applications in pharmaceutical field.

Keywords: Spray drying, atomization, pharmaceutical.

\section{Introduction}

The development of spray drying equipment and techniques evolved over a period of several decades from the 1870s through the early 1900s. Spray drying comes of age during World War II, with the sudden need to reduce the transport weight of foods and other materials. This technique enables the transformation of feed from a fluid state into dried particulate form by spraying the feed into a hot drying medium. It is a continuous particleprocessing drying operation. The feed can be a solution, suspension, dispersion or emulsion. The dried product can be in the form of powders, granules or agglomerates depending upon the physical and chemical properties of the feed, the dryer design and final powder properties desired (Michael, 1993).

Spray drying process mainly involves five steps:

(i) Concentration: feedstock is normally concentrated prior to introduction into the spray dryer.

(ii) Atomization: the atomization stage creates the optimum condition for evaporation to a dried product having the desired characteristics.

(iii) Droplet-air contact: in the chamber, atomized liquid is brought into contact with hot gas, resulting in the evaporation of $95 \%+$ of the water contained in the droplets in a matter of a few seconds.

iv) Droplet drying: moisture evaporation takes place in two stages- 1) during the first stage, there is sufficient moisture in the drop to replace the liquid evaporated at the surface and evaporation takes place at a relatively constant rate (Keey \& Pham, 1976), and 2) the second stage begins when there is no longer enough moisture to maintain saturated conditions at the droplet surface, causing a dried shell to form at the surface. Evaporation then depends on the diffusion of moisture through the shell, which is increasing in thickness.

(v) Separation: cyclones, bag filters, and electrostatic precipitators may be used for Feed

Short communication

CIndian Society for Education and Environment (iSee) the final separation stage. Wet Scrubbers are often used to purify and cool the air so that it can be released to atmosphere.

Spray drying process (Fig.1) have advantages that can be designed to virtually any capacity required. Feed rates range from a few pounds per hour to over 100 tons per hour. Operation is continuous and adaptable to full automatic control (Gharsallaoui et al., 2007). It can be used with both heat-resistant and heat sensitive products. Nearly spherical particles can be produced. There are some limitation that includes limited versatility in producing particles or structures with the complex morphologies, and rapid drug release rates often exhibiting a burst effect (Katta \& Gauvin, 1976).

\section{Design and critical elements of spray drying Atomizers}

The "heart" of any spray dryer is the atomizer, small in size, big in importance, installing the right atomizer is essential to spray drying success.

The atomizer must fulfill several important functions which are summarized below:

i. It must disperse the feed material into small droplets, which should be well distributed within the dryer and mixed thoroughly with the hot gas.

ii. The droplets produced must not be so large that they are incompletely dried, nor so small that product recovery is difficult. Small particles may also overheat and become scorched.

iii. The atomizer must also act as a metering device, controlling the rate at which the material is fed into the dryer: a) Air atomization or two fluid nozzles, b) Airless atomization nozzles, c) Pressure nozzles, d) Rotary or disk nozzles and, d) Ultrasonic nozzles.

Air flow

a) Co-current flow: in a co-current dryer, the spray is directed into the hot air entering the dryer and both pass through the chamber in the same direction.

b) Counter-current flow: in this dryer design, the spray and the air are introduced at opposite ends of the dryer, with the atomizer positioned at the top and the air entering at the bottom.

c) Mixed flow: dryers of this type combine both cocurrent and counter current flow. In a mixed 
flow dryer, the air enters at the top and the atomizer is located at the bottom.

\section{Spray drying chamber}

Air within the chamber maintains a flow pattern, preventing deposition of partially dried product on the wall or atomizer (Ronald, 1997). Air movement and temperature of inlet air influence the type of final product.
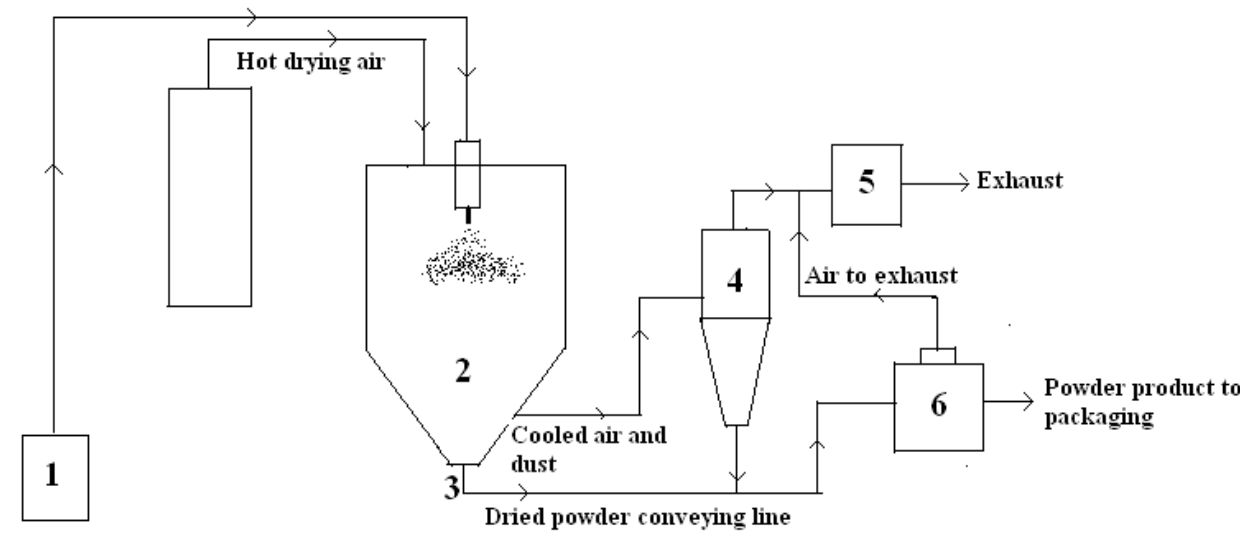

\section{Types of spray drier} Single stage dryer (Fig.2)

(1-Feedstock; 2-drying chamber; 3-dried product; 4cyclone; 5-wet scrubber; 6-bag filter)

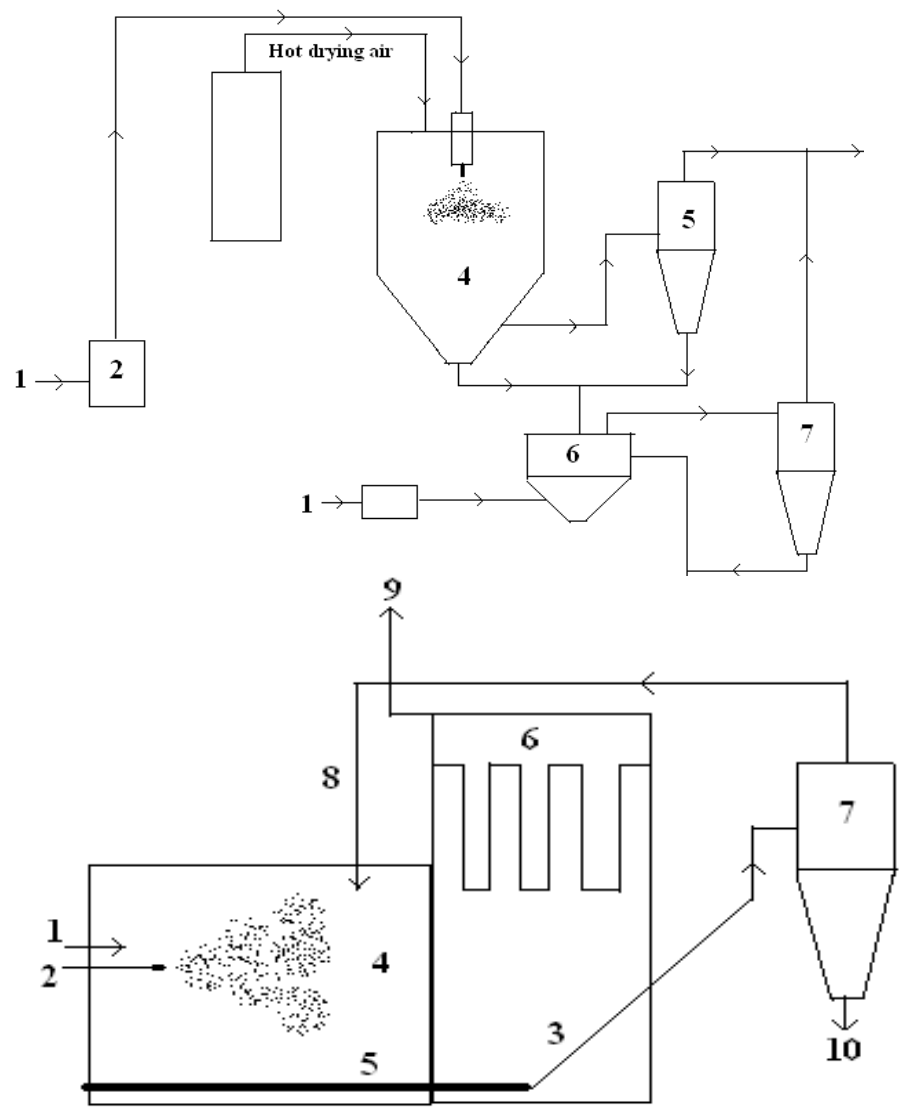

Vol.2 No.10 (Oct 2009)

ISSN: 0974- 6846

Two stage dryer (Fig.3)

Two stage dryers allow the use of lower temperatures in the dryer, making the design a good choice for products that are particularly heat sensitive (Katta \& Gauvin, 1976) (1-air; 2-feedstock; 3-dried product; 4drying chamber; 5 -cyclone; 6 -stationary fluid bed; 7-fluid bed cyclone) .

\section{Horizontal dryer (Fig.4)}

The components are: 1-drying air; 2-feedstock; 3-pneumatic conveyor; 4-drying chamber; 5powder conveyor; 6-filter bags; 7cyclone; 8-dust return; 9-exhaust to atmosphere; 10-dried powder. Vertical dryer

It is suited for both non-fat and fat-containing products, producing non-agglomerated and agglomerated free-flowing powders. Manufacturers of vertical spray dryers include Stork, Niro and APV Anhydro.

Fluidized spray drier (Fig.5)

The Fluidized Spray Dryer combines spray drying and fluid bed drying technologies and offer excellent product flexibility and excellent thermal efficiency. Sticky products can be dried successfully, and the concept is ideal for drying heat sensitive products, and improved aroma retention is accomplished (Sommerfeld \& Blei, 1992).

\section{Multi stage drier}

The process produces non-dusty, free flowing agglomerated powders with high flavor retention. It operates with low outlet-temperatures, achieving high thermal efficiency. This design concept is successful for drying high fats, hygroscopic, and sticky products that are difficult to handle in more conventional designs.

Compact Spray Dryer

Atomization is created by either a rotary atomizer or spray nozzle atomizer. The location of the fluid bed within the drying chamber achieves drying at lower temperature levels. It results in higher thermal efficiencies and cooler conditions for powder handling.

Integrated filter drier

IFD ${ }^{\text {TM }}$ Integrated Filter Dryer - Combines an integrated fluid bed and filter arrangement. It is an adaptable and flexible spray dryer for the food ingredients, food, dairy, chemical, and pharmaceutical industries.

The Integrated Filter Dryer (IFD ${ }^{\text {TM}}$ ): features and benefits includes: improves powder quality, no handling of product outside drying chamber, reduced noise level and lower energy consumption.

FIL TERMAT@ Dryer

The FILTERMAT $®$ Spray Dryer is frequently used in food and dairy applications. It operates at a low outlet temperature, achieving high thermal efficiency. It is the
Short communication

CIndian Society for Education and Environment (iSee)
Patel et al. Indian J.Sci.Technol. 
recommended system for drying high fat, sugar-based, hydrolyzed, and fermented products.

\section{Critical parameters of spray drying}

a) Inlet temperature of air: higher the temperature of inlet air, faster is the moisture evaporation but the powder is subjected to higher temperature, which may distort the chemical/physical properties of heat sensitive product (Michael, 1993).

b) Outlet temperature of air: it govern the sizing of powder recovery equipments, higher is the outlet air temperature larger will be the size of powder recovery equipment and conveying ducts and plenums (Maury et al., 2005). Outlet air temperatures control final moisture content of powder.

c) Viscosity: high viscosity hinders correct drop formation. As the viscosity is lowered, less energy or pressure is required to form a particular spray pattern.

d) Solid content: care must be taken with high solid loadings (above $30 \%$ ) to maintain proper atomization to ensure correct droplet formation.

e) Surface tension: addition of a small amount of surfactant can significantly lower the surface tension. This can result in a wider spray pattern, smaller droplet size, and higher drop velocity.

f) Feed temperature: as the temperature of a solution to be sprayed is increased, the solution may easily dry as it brings more energy to the system.

g) Volatility of solvent: a high volatility is desirable in any drying process. Unfortunately, choices are limited today. In many cases, these restrict the solvent choice to water.

h) Nozzle material: most pharmaceutical applications use stainless steel inserts. However, tungsten carbide nozzles are often available and have excellent resistance to abrasion and good corrosion resistance for most feedstock.

\section{Innovations in spray drying}

Sterile spray drying for stable injectable liquid formulation

Soluble glass microspheres forming a monodisperse suspension in anhydrous fluorocarbon liquid because the microspheres are solid, their density can be precisely controlled to match that of the surrounding liquid (Buckton et al., 2002; Roser, 2005). Such suspensions are physically stable and the particles neither settle nor float in the liquid phase.

Foam spray drying

In this method liquid food is foamed, such as milk or coffee, before spraying it into the drier. The result is faster drying rate from the expanded foamed droplet surface area, and lighter density dried product. This is known as foam-spray drying (Hanrahan \& Webb, 1961).

Spray drying for the production of crystalline products

Spray drying is known to produce predominately amorphous material due to the almost instantaneous transition between liquid and solid phases. However, spray drying can also be used to obtain crystalline products (Shoyele \& Cawthorne, 2006). To achieve such a goal, the product is fed in a crystalline suspension, instead of a solution, to the drying chamber. Feeding the crystals in the right form allows spray drying to fine tune crystal size distribution and final content of residual solvents (Jorge \& Felipe, 2004).

\section{Applications of spray drying in pharmaceutical field Effect of spray drying on powder properties}

Many spray drying operations produce spherical particles while others result in non-spherical particles. Particles may be hollow or solid. Pressure spray nozzles can produce particles ranging in size from 20 to 600 microns. Two-fluid nozzles generally produce particles with sizes in the range from 10 to 200 microns and larger (Katta \& Gauvin, 1976; Sommerfeld \& Blei, 2001). Rotary atomizers produce more uniform particle sizes compared to pressure atomizers. Co-current dryers produce powders with lower bulk densities than counter-current dryers.

\section{Granulation}

In general, a spray dried granulation has improved flow, better distribution of drug, colors, etc. and requires less lubricant than wet massed products (Michael, 1993). Spray drying results in a shell of concentrated binder at the surface of the granular material, providing strong tablets and maximum use of binder.

\section{Bioavailability}

With spray drying one can co-precipitate an API with a polymer in a stable amorphous solid dispersion, thereby greatly improving the dissolution rate of many drug substances, including tolbutamide, indomethacin and ibuprofen (Gonnissen et al., 2008). Complexes of paracetamol and diazepam have been prepared with $\mathrm{p}$ cyclodextrin.
Short communication

CCIndian Society for Education and Environment (iSee)
"Spray drying"

http://www.indjst.org
Patel et al. Indian J.Sci.Technol. 


\section{Encapsulation}

With a cocurrent drier, heat exposure is minimized. The product is usually recovered about $15^{\circ} \mathrm{C}$ below the outlet temperature (Wan et al., 1992). This has been applied to microencapsulation of products such as antibiotics, vaccines, peptides and proteins.

Inhalation

Highly specialized spray drying nozzles that give increased particle engineering capabilities, even on largescale- making it possible to accurately manipulate aerodynamic particle size and properties. Spray drying technologies make it easier than ever to efficiently produce therapies in the form of free-flowing particles that are ideally suited for inhalation (Seville et al., 2007).

\section{Control release products}

Creating a shell-like structure around the granular allows spray drying to be used for the manufacture of controlled-release products.

\section{Future impacts}

Spray drying is presently one of the most exciting technologies for the pharmaceutical industry, being an ideal process where the end-product must comply with precise quality standards regarding particle size distribution, residual moisture content, bulk density and morphology. The production of particles from the process of spraying has gained much attention in recent years.

Multistage processes, new spray techniques, and temperature-gradient systems hold promise for future pharmaceutical application (Masters, 1991). Classic equipment designs are being used more and more in the United States as a means for preparing pharmaceutical products of various types. Their versatile output capacity, continuous operation and controllability are desirable features.

\section{References}

1. Buckton G, Chidavaenzi $O$ and Koosha F (2002) The effect of spray drying feed temperature and subsequent crystallization conditions on the physical form of lactose. AAPS Pharm. Sci. Tech. 3(4), 17.

2. Gharsallaoui A, Roudaut $G$, Chambin O, Voilley $A$ and Saurel R (2007) Applications of spray-drying in microencapsulation of food ingredients: an overview. Food Res. Intl. 40, 1107-1121.

3. Gonnissen Y, Verhoeven E, Peeters E, Remon JP and Vervaet $C$ (2008) Coprocessing via spray drying as a formulation platform to improve the compactability of various drugs. Eur. J. Pharmac. \& Biopharma. 69, 320-334.

4. Hanrahan FP and Webb BH. (1961) USDA Develops foam-spray drying. Food Eng. 33(8), 37.

5. Jorge MCP and Filipe G (2004) Spray drying technology for better API crystals. Process Development. 38-39. www.sp2.uk.com

6. Katta S and Gauvin W (1976) Basic concepts of spray dryer design. A/CHE J. 22 (4), 713-724.
Vol.2 No.10 (Oct 2009)

ISSN: 0974- 6846

7. Keey RB and Pham QT (1976) Behavior of spray driers with nozzle atomizers. Chem. Engg. 311, 516521.

8. Masters K (1991) Spray drying handbook, John Wiley \& Sons, $N Y, 5^{\text {th }}$ edition.

9. Maury M, Murphy K, Kumar S, Shi L and Lee G (2005) Effects of process variables on the powder yield of spray-dried trehalose on a laboratory spraydryer. Eur. J. Pharmac. \& Biopharma, 59, 565-573.

10. Michael JK (1993) Spray drying and spray congealing of pharmaceuticals. In: Encyclopedia of pharmaceutical technology. Marcel Dekker INC, NY, 14, 207-221.

11. Ronald CD (1997) Spray drying innovative use of an old process. Design Elements. 7, 97-113.

12. Roser B (2005) Sterile spray drying for stable liquid $21^{\text {st }}$ century pharmaceuticals. In: Innovations in pharmaceutical technology. pp: 50-54.

13. Seville PC, Li Hy and Learoyd TP (2007) Spray dried powders for pulmonary drug delivery. Crit. Rev. Ther. Drug Carrier Syst. 24 (4), 307-360.

14. Shoyele SA and Cawthorne S (2006) Particle engineering techniques for inhaled biopharmaceuticals. Adv. Drug Delivery Rev. 58, 1009-1029.

15. Sommerfeld M and Blei S (1992) Lagrangian modeling of agglomeration during spray drying processes. Encyclopedia of Pharma. Technol. 6, 171-173.

16. Vehring $R$ (2008) Pharmaceutical particle engineering via spray drying. Pharm. Res. 25 (5), 999-1022.

17. Wan LS, Heng PW, Chia CG and Cececilia GH (1992) Spray drying as a process for encapsulation and the effect of different coating polymers. Drug. Dev. Ind .Pharm. 18(9), 997-1011.
Patel et al. Indian J.Sci.Technol. 